\title{
Carcinoma Buccal Mucosa Presenting as Ocular Metastasis to the Choroid
}

\begin{abstract}
Metastasis to eyes from a head and neck carcinoma is a rare event. A 62-year-old male presented with carcinoma of the left buccal mucosa. The patient was operated and was pathological stage pT2N0Mx. The patient was advised adjuvant postoperative radiotherapy (60Gray/30\#). During the treatment, he presented with progressive diminution of vision in the left eye. He was investigated and was found to have choroidal secondaries in the left eye involving $80 \%$ of the globe. On positron emission tomography-computed tomography scan, no metastatic lesion was found elsewhere in the body. Ocular metastasis in a case of T2NOMx without pulmonary metastasis is a rare event.
\end{abstract}

Keywords: Carcinoma buccal mucosa, choroidal metastasis, distant metastasis, secondaries in eyes

\section{Introduction}

Secondaries are most common ocular neoplasms, and the choroid, being a highly vascular layer, is the most common part of eye for metastasis. ${ }^{[1]}$ Metastasis outnumbers the primary ocular neoplasms, for example, retinoblastoma and malignant melanoma. The common sources of ocular metastasis are primaries from the breasts $(38 \%-40 \%)$, lungs $(20 \%-29 \%)$, gastrointestinal and genitourinary malignancies. Choroidal melanoma and hemangioma are important differential diagnoses which mimic this condition. Ocular metastasis from a primary head and neck cancer is a rarity. The common distant sites involved by head and neck cancer are lungs, mediastinal nodes, bones, and liver. ${ }^{[1]}$ Choroidal deposits from a carcinoma of buccal mucosa are extremely rare. We report a case of carcinoma buccal mucosa metastasizing to the choroid. The purpose of this report is to draw attention toward a rare and unique presentation of head and neck cancer, where choroidal metastasis was seen without evidence of any other distant metastasis in a patient of early oral cavity carcinoma.

\section{Case Report}

A 62-year-old male diagnosed with carcinoma of the left buccal mucosa in September 2012. He was operated upon (wide local excision of left buccal

This is an open access journal, and articles are distributed under the terms of the Creative Commons Attribution-Non Commercial-ShareAlike 4.0 License, which allows others to remix, tweak, and build upon the work non-commercially, as long as appropriate credit is given and the new creations are licensed under the identical terms.

For reprints contact: reprints@medknow.com mucosa with left hemimandibulectomy and modified neck dissection type II) in September 2012. Histopathology report suggested squamous cell carcinoma of size $2.5 \mathrm{~cm} \times 2.0 \mathrm{~cm} \times 1.7 \mathrm{~cm}$. All 31 lymph nodes dissected from left level I to $\mathrm{V}$ were free $(0 / 31)$ of metastasis. No perineural or lymphovascular invasion was seen. Overlying skin was free. Depth of invasion was $0.7 \mathrm{~cm}$. All the margins and cut end of bone were free. It was pathological stage pT2N0Mx. The metastatic workup at the time of surgery was negative for any distant metastasis. The patient was advised adjuvant radiotherapy (60 Gray in 30 fractions) from October 20,2012 on a $6 \mathrm{MV}$ linear accelerator with a two field wedge plan (Antero Posterior and Lateral field). During treatment (after 28 Gray/14 fractions), the patient presented with painless, gradually progressive diminution of vision of the left eye. A thorough ophthalmological examination was done which included slit lamp examination, ultrasonography (USG) of eyes, and magnetic resonance imaging (MRI) of both eyes and brain. Biopsy was not possible from the choroidal mass. The USG scan [Figure 1] revealed choroidal lesion suggestive of secondaries in the left eye. MRI brain and both eyes [Figures 2 and 3] showed the presence of altered signal intensity in the posterior chamber of the left eye which was hyperintense in T1-weighted sequence and hypointense on T2-weighted sequence.

\footnotetext{
How to cite this article: Jyoti $\mathrm{P}$, Ashutosh $\mathrm{S}$, Maitrik JM, Ubrangala KS. Carcinoma buccal mucosa presenting as ocular metastasis to the choroid. Indian J Med Paediatr Oncol 2018;39:395-7.
}

\section{Poddar Jyoti, Sharma Ashutosh, J Mehta Maitrik, Kunikullaya Suryanarayana Ubrangala}

Department of Radiotherapy, Gujarat Cancer and Research Institute, Ahmedabad, Gujarat, India

Address for correspondence: Dr. Poddar Jyoti, Department of Radiotherapy, Gujarat Cancer and Research Institute, Ahmedabad, Gujarat, India.

E-mail: jyopoddar@gmail.com

Access this article online

Website: www.ijmpo.org

DOI: 10.4103/ijmpo.ijmpo_58_17 Quick Response Code:

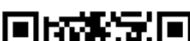




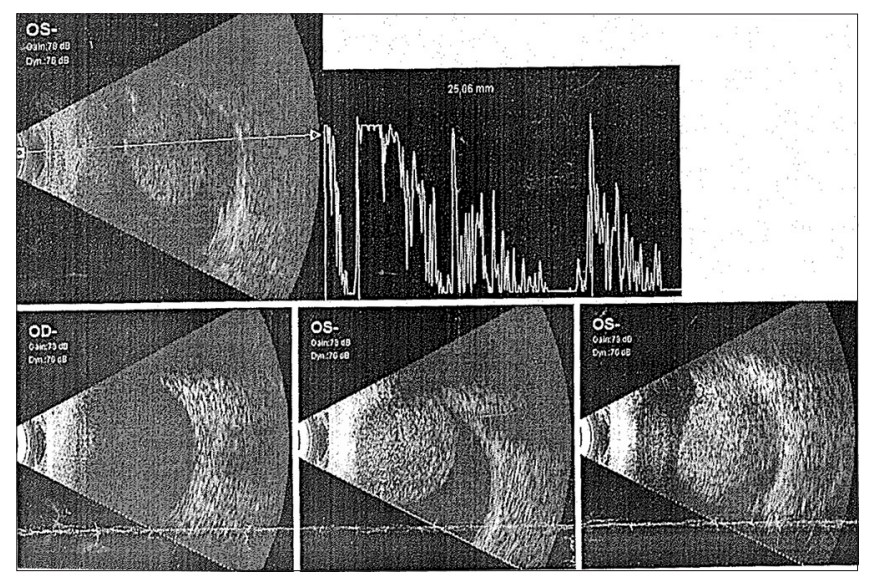

Figure 1: Ultrasonography scan of the left eye showing mass in choroid

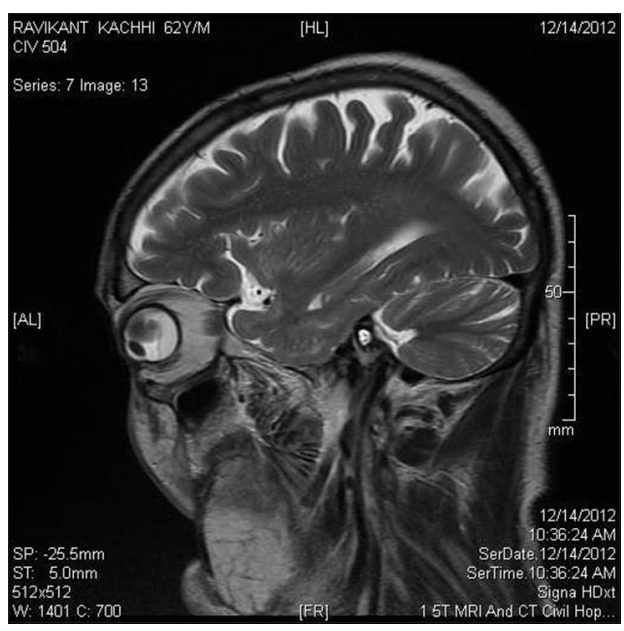

Figure 2: Magnetic resonance imaging scan of the left eye

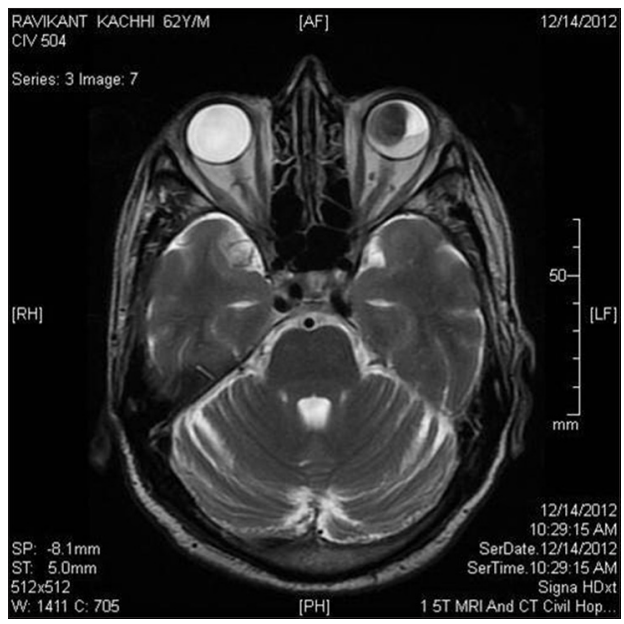

Figure 3: Magnetic resonance imaging scan of both eyes and brain

A solitary deposit in the left choroid involving $80 \%$ of the globe with secondary retinal detachment was seen. There was no other choroidal or brain metastasis. Positron emission tomography-computed tomography (PET-CT) evaluation showed metastatic disease in the left choroid, with no other involved site elsewhere in the body.
The radiotherapy treatment for the carcinoma buccal mucosa was completed by the time the metastatic disease was confirmed. In view of stage IV disease, the patient was advised chemotherapy, i.e., paclitaxel and carboplatin. $\mathrm{He}$ received three cycles and had no symptomatic improvement. The patient was then lost to follow-up.

\section{Discussion}

Ocular neoplasm may be a primary or secondary. The secondaries are far more common than the primary neoplasm. ${ }^{[2]}$ The choroid is the highly vascular layer of the eye and thus the most common site for homing of the malignant cells although the retina and ciliary body can also be involved. Even in the malignancies where ocular metastasis is common such as carcinoma breast, carcinoma lung, and carcinoma of gastrointestinal tract, the first sites of metastasis are the lungs, brain, bones, and liver before the eyes being affected. Development of ocular secondary without involvement of all these sites is rare, and development of ocular metastasis without development of brain metastasis is even rarer. ${ }^{[2]}$

Unilateral choroidal metastasis is more common than bilateral metastasis. ${ }^{[3]}$ Some studies have indicated that metastatic disease is more common in the left eye as the left common carotid ascends directly off the aorta; tumor cells from the circulation could have a more direct path to left orbit. Diagnosing the disease is often challenging. Retinal detachment, intravitreal, and subretinal hemorrhage are the common complications of choroidal metastasis. Retinal detachment gives rise to visual loss which is very common in these cases. ${ }^{[4]}$

Ultrasonography shows diffuse choroidal thickening with high or medium amplitude echoes and may mimic choroidal melanoma which is an important differential diagnosis. USG can provide an idea about the local extent of the mass but cannot differentiate between a primary and metastasis.

Clinical profile, MRI, and fludeoxyglucose PET CT can help in differentiating this condition from the common differential diagnoses, for example, choroidal melanoma and hemangioma, although none of these investigations are diagnostic. The treatment options after diagnosis of distant metastasis are very limited and depend mainly upon the distant site of metastasis. The treatment is mainly palliative with the aim of symptomatic relief.

Palliative radiotherapy can be delivered for pain or proptosis. It may improve symptoms in $80 \%$ of patients but may or may not restore vision. Chemotherapy for systemic disease can help to control ocular metastasis. The most active chemotherapeutic agents in metastatic head and neck cancers are platin, taxanes, 5-fluorouracil, and cetuximab ${ }^{[5-8]}$ Palliative surgery comes into play for intractable ocular morbidities such as proptosis and pain which need urgent intervention. Hormone therapy can help in hormone-sensitive tumor like carcinoma breast. ${ }^{[9]}$ Patient's 
performance status, life expectancy, status of the primary tumor, and possible side effects of the intended treatment determines the line of management. The overall prognosis for such patients remains poor ${ }^{[10]}$ However, when the primary disease is under control and eye is the only metastatic site, as in this case, or in carcinoma breast patients, where overall survival has improved dramatically in recent times, the search of some novel targeted treatment, new investigational agents, and advances in radiotherapy techniques may lead to better quality of life and preservation of ocular function.

\section{Conclusion}

Although ocular metastasis is not common in head and neck cancer, any patient having visual complaints should be thoroughly investigated. In rare instances, it can also be the first manifestation of an underlying undiagnosed malignancy. Although it is difficult to cure, early diagnosis can lead to prompt interventions which can lessen the suffering of the patient and restore or preserve the remaining visual function.

\section{Financial support and sponsorship}

Nil.

\section{Conflicts of interest}

There are no conflicts of interest.

\section{References}

1. John SS, Horo S, Braganza AD, Kuriakose T. Bilateral choroidal metastasis from carcinoma of the submandibular gland. Indian J
Ophthalmol 2008;56:75-6.

2. Solav S, Bhandari R, Sowani A, Saxena S. Choroidal metastasis from carcinoma of breast detected on F18-FDG PET CT scan: A case report and review of literature. Indian $\mathrm{J}$ Nucl Med 2010;25:160-3.

3. Valenzuela AA, Archibald CW, Fleming B, Ong L, O'Donnell B, Crompton JJ, et al. Orbital metastasis: Clinical features, management and outcome. Orbit 2009;28:153-9.

4. Volpe NJ, Albert DM. Metastases to the uvea. In: Albert DM, Jakobiec FA, editors. Principles and Practices of Ophthalmology. Philadelphia, PA: WB Saunders Company; 1995. p. 3260-70.

5. Forastiere AA, Takasugi BJ, Baker SR, Wolf GT, Kudla-Hatch V. High-dose cisplatin in advanced head and neck cancer. Cancer Chemother Pharmacol 1987;19:155-8.

6. Vermorken JB, Trigo J, Hitt R, Koralewski P, Diaz-Rubio E, Rolland F, et al. Open-label, uncontrolled, multicenter phase II study to evaluate the efficacy and toxicity of cetuximab as a single agent in patients with recurrent and/or metastatic squamous cell carcinoma of the head and neck who failed to respond to platinum-based therapy. J Clin Oncol 2007;25:2171-7.

7. Guardiola E, Peyrade F, Chaigneau L, Cupissol D, Tchiknavorian X, Bompas E, et al. Results of a randomised phase II study comparing docetaxel with methotrexate in patients with recurrent head and neck cancer. Eur J Cancer 2004;40:2071-6.

8. Jacobs C, Lyman G, Velez-García E, Sridhar KS, Knight W, Hochster $\mathrm{H}$, et al. A phase III randomized study comparing cisplatin and fluorouracil as single agents and in combination for advanced squamous cell carcinoma of the head and neck. J Clin Oncol 1992;10:257-63.

9. Samanta DR, Bose C, Bhuyan R, Mishra SR, Senapati SN. Ophthalmic metastasis in squamous cell carcinoma of head and neck: A study on two patients. Int J Sci Stud 2015;3:230-3.

10. Ahmad SM, Esmaeli B. Metastatic tumors of the orbit and ocular adnexa. Curr Opin Ophthalmol 2007;18:405-13. 